\title{
GENERALIZED KINETIC MASTER PLOTS FOR THE THERMAL DEGRADATION OF POLYMERS FOLLOWING A RANDOM SCISSION MECHANISM.
}

Pedro E. Sánchez-Jiménez*, Luis A. Pérez-Maqueda, Antonio Perejón and José M. Criado.

Instituto de Ciencia de Materiales de Sevilla, C.S.I.C.-Universidad de Sevilla, C. Américo Vespucio $n^{\circ} 49,41092$ Sevilla, Spain

\begin{abstract}
In this paper, the $f(\alpha)$ conversion functions for random scission mechanisms have been proposed in order to allow for the construction of generalized master plots suitable for these kind of mechanisms. The master plots have been validated by its application to simulated data and to the thermal degradation of polybutylenterephtalate, polyethylene and polytetrafluoroethylene.
\end{abstract}

Keywords: Kinetics, Master plots, Random scission, Polymer degradation, Mechanisms

\footnotetext{
* Corresponding author. Tel +34954489548 Fax +34954460665

e-mail address: pedro.enrique@icmse.csic.es
} 


\section{Introduction}

The kinetic modelling of solid state reactions keeps raising a broad interest in materials science and engineering. A reliable evaluation of the kinetic parameters that govern a process provides a valuable insight into the mechanism followed by the reaction. A proper kinetic analysis calls for the determination of the kinetic triplet, namely, the activation energy, E; the pre-exponential factor, A; and the kinetic model, $f(\alpha)$. This latter parameter, also known as conversion function, is an algebraic expression that is associated with the physical model that describes the kinetics of a reaction. ${ }^{1-2}$ A number of different methods have been developed over the years for extracting kinetic information from experimental data, many requiring the experimental data to be obtained under certain experimental conditions. ${ }^{3-12}$ Thus, isothermal, non isothermal, or the recent combined analysis methods have been proposed. Recently, the so called "model-free" methods, that allow determining the activation energy of a process as a function of the degree of conversion without any previous assumption of the kinetic model, have attained great popularity. ${ }^{12-19}$ However, they do not directly yield the reaction kinetic model, although methods for its evaluation have been developed with

the use of master plots. ${ }^{20-23}$ Master plots are reference theoretical curves that depend on the kinetic model but are independent of the kinetic parameters, E and A. Experimental data can easily be transformed into experimental master plots and compared with the theoretical ones determined for the different kinetic models.

Kinetic Analysis is equally important in the field of thermal stability of polymers. The development of workable models able to describe the decomposition processes and to determinate materials response to different thermal conditions has been the concern of many authors and extensive work has been produced during last decades. ${ }^{24}$ However, degradation of polymers is a complex phenomenon and despite the great deal of 
research performed on this subject, a high controversy still remains. The difficulty of determining the proper kinetic model of polymer degradation reaction has prompted that most of the works found in the literature resort to model-free methods, ${ }^{19,25-28}$ or just assume first or "n-order" kinetic models without reporting arguments that support this assumption. $^{29-37}$ However, a recent work has proven that thermal degradation of polymers do not necessarily take place through first or "n-order" kinetics and other mechanisms such as diffusion or random scission can control the decomposition reaction. ${ }^{38}$ The use of master plots in thermal degradation of polymers would help to discriminate the kinetic model without the previous assumption of a particular conversion function that does not guarantee the proper description of the degradation mechanism. While a set of master plots applicable to experimental data recorded under any heating profile has already been proposed in this journal, ${ }^{23}$ they cannot be applied as proposed to random scission kinetic models due to the impossibility to express $f(\alpha)$ as a function of the reacted fraction in a closed form. As random scission is one of the most usual mechanisms in degradation of polymeric materials, ${ }^{36,39-45}$ the extension of the master plots in order to cover these situations is of the utmost interest.

In this work, the original Simha-Wall equation for depolymerisation processes ${ }^{46}$ has been reformulated in such a way that the reaction rate can be directly expressed as a function of $f(\alpha)$, time or temperature. Then, making use of the new equations, the generalized master plots ${ }^{23}$ have been extended to random scission mechanisms, The evaluation of the proposed random scission kinetic model and its corresponding master plot has been carried out by simulated and experimental curves alike. The latter were obtained from the thermal degradation of three commercial polymers: polybutylenterephtalate (PBT), polyethylene (PE) and polytetrafluoroethylene (PTFE). 


\section{Proposal of a new kinetic model for random scission mechanisms}

The reaction rate, $\mathrm{d} \alpha / \mathrm{dt}$, can be described by the following equation:

$\frac{d \alpha}{d t}=k f(\alpha)=A \exp (-E / R T) f(\alpha)$

where $A$ is the Arrhenius pre-exponential factor, $R$ is the gas constant, $E$ the activation energy, $\alpha$ the reacted fraction, $T$ is the process temperature and $f(\alpha)$ the kinetic model, which accounts for the reaction rate dependence on $\alpha$. Table 1 shows the functions corresponding to the most common models in the literature. Decomposition of a polymer by random scission implies a random cleavage of bonds along the polymer chains, producing fragments of progressively shorter length that will eventually evaporate when the size is small enough. ${ }^{24}$ According to Simha-Wall ${ }^{46}$, the cleavage of bonds follows first order kinetics and the following expressions hold true:

$$
\begin{aligned}
& \frac{d x}{d t}=k(1-x)=A e^{\frac{-E}{R T}}(1-x) \\
& 1-\alpha=(1-x)^{L-1}\left[1+x \frac{(N-L)(L-1)}{N}\right]
\end{aligned}
$$

where $x, N$ and $L$ are the fraction of bonds broken, the initial degree of polymerization and the minimum length of the polymer that is not volatile, respectively. As $L$ is usually negligible in comparison to $N$, Eq. (3) can be simplified to:

$$
\alpha=1-(1-x)^{L-1}[1+x(L-1)]
$$


Most thermal degradation studies are carried out by thermogravimetry because the mass lost can be easily related to the conversion. However, in the case of random scission mechanisms only the broken bonds that produce fragments small enough would actually evaporate and therefore be detected as mass loss. That problem is solved by Eq. (4), which establishes a relationship between the detected mass loss and the actual reacted fraction in terms of fraction of bonds broken. This relationship is shown graphically in Figure 1, assuming $\mathrm{L}$ values ranging from 2 to 8 . However, as $x$ cannot be measured by conventional techniques and $L$ is very difficult to obtain experimentally, the application of Eq. (4) has been severely limited. Nevertheless, by differentiating Eq. (4), and incorporating Eq. (2) we get:

$$
\frac{d \alpha}{d t}=L(L-1) x(1-x)^{L-2} k(1-x)
$$

This way, taking into account Eq. (1), we can get from Eq. (5) the conversion function $f(\alpha)$ which is characteristic of a random scission model:

$$
f(\alpha)=L(L-1) x(1-x)^{L-1}
$$

Many kinetic analysis methods involve the fitting of experimental data to a certain kinetic model. This requires the $f(\alpha)$ functions for the different models to be previously known. Thus, if random scission mechanisms are to be used in this way, $f(\alpha)$ must be determined. However, a symbolic solution can only be reached for $\mathrm{L}=2$. In this latter case, from Eq. (1) and Eq. (6) we obtain:

$$
\frac{d \alpha}{d t}=2 k\left(\alpha^{1 / 2}-\alpha\right)
$$

Therefore, $f(\alpha)$ must be: 


$$
f(\alpha)=2\left(\alpha^{1 / 2}-\alpha\right)
$$

Taking into account the relationship between $x$ and $\alpha$ as established in Eq. (4), for any given $L$ and assigning values to $\alpha$, from Eq. (4) and (6) it is possible to calculate numerically the corresponding $f(\alpha)$ conversion functions, which are plotted against $\alpha$ in Figure 2a. For the sake of comparison, Figure 2 also includes the $f(\alpha)$ conversion functions corresponding to the most common kinetic models in literature: "n order" (2b), diffusion controlled (2c) and nucleation and growth kinetic models (2d). Random scission functions have a characteristic shape which is quite different from the other models. Since the results of a kinetic analysis are heavily dependent on the kinetic model considered, random scission driven reactions could never be adequately described by other models, and in particular by "n-order" models, as it is often done in literature, and doing so will only result in obtaining incorrect kinetic parameters. However, the random scission kinetic model could be described by the modified SestakBerggren expression that was proposed as a fitting equation for the combined kinetic analysis procedure. ${ }^{42,47}$

\section{Generalized Master Plots}

In a previous paper the generalized kinetic equations introduced by Ozawa ${ }^{48}$ was used for the proposal of universal master plots that were valid for experimental data recorded under any heating profile. ${ }^{23}$ Thus, if the generalized time is defined as ${ }^{49}$ :

$$
\theta=\int_{0}^{t} \exp \left(\frac{-E}{R T}\right) d t
$$


where, considering the integral of Eq. (1), it is clear that $\theta$ represents the time needed to reach a certain $\alpha$ value at infinite temperature. By differentiating Eq. (9) the following equation can be obtained:

$$
\frac{d \theta}{d t}=\exp \left(\frac{-E}{R T}\right)
$$

The combination of Eq. (1) and Eq. (10) leads to:

$$
\frac{d \alpha}{d \theta}=A f(\alpha)
$$

which can also be expressed in the following way:

$$
\frac{d \alpha}{d \theta}=\frac{d \alpha}{d t} \exp \left(\frac{-E}{R T}\right)
$$

$d \alpha / d \theta$ being the generalized reaction rate that, according to Eqs. (1), (11) and (12), represents the reaction rate extrapolated at infinite temperature as previously shown by Ozawa. $^{49}$ Since the previous knowledge of the activation energy allows for the extrapolation to infinite temperature of experimental data recorded under any heating profile, Eq. (12) should be valid for the analysis of any data, independently of the temperature profile under which they were obtained. From Eq. (11) and taking $\alpha=0.5$ as a reference we get:

$$
\frac{d \alpha / d \theta}{(d \alpha / d \theta)_{0.5}}=\frac{f(\alpha)}{f(0.5)}
$$

As $f(0.5)$ is constant for a certain kinetic model, Eq (13) indicates that for a given $\alpha$, the reduced-generalized reaction rate, $(d \alpha / d \theta) /(d \alpha / d \theta)_{\alpha=0.5}$, would be equivalent to $f(\alpha) / f(0.5)$ when the proper $f(\alpha)$ is selected to describe the process. From Eq. (12) and 
Eq. (13), the relationship between the generalized reaction rate and the experimental data can be established:

$\frac{d \alpha / d \theta}{(d \alpha / d \theta)_{0.5}}=\frac{d \alpha / d t}{(d \alpha / d t)_{0.5}} \frac{\exp (E / R T)}{\exp \left(E / R T_{0.5}\right)}$

where $T_{0.5}$ represents the temperature corresponding to $\alpha=0.5$. In the case of experimental data obtained under isothermal conditions, the exponential term of the second half in Eq. (14) cancels and the equations becomes:

$\frac{d \alpha / d \theta}{(d \alpha / d \theta)_{0.5}}=\frac{d \alpha / d t}{(d \alpha / d t)_{0.5}}$

On the other hand, for experimental data recorded under non isothermal conditions, the previous knowledge of the activation energy is required in order to construct the experimental master plots. By plotting together versus $\alpha$ the generalized reaction rate, as calculated from Eq. (14) (or Eq. (15) for isothermal conditions), and the fraction $f(\alpha) / f(0.5)$, corresponding to different theoretical kinetic models, it is possible to deduce by comparison the kinetic model followed by the process. It must be noted that, according to Eq. (14), for non isothermal experiments a single activation energy value is assumed. Therefore, for this analysis procedure to be valid, the studied process must obey single step kinetics. Here resides the importance of the previous isoconversional analysis, checking that the activation energy does not vary with alpha in a significant way. 


\section{Random Scission Master Plots}

The reduced-generalized reaction rate for random scission models is derived from Eq.

(5) by taking $\alpha=0.5$ as a reference:

$$
\frac{(d \alpha / d t)}{(d \alpha / d t)_{0.5}}=\frac{x(1-x)^{L-2}}{x_{0.5}\left(1-x_{0.5}\right)^{L-2}} \frac{k(1-x)}{k\left(1-x_{0.5}\right)}
$$

According to $\mathrm{Eq}(15)$, in the case of isothermal conditions, $(d \alpha / d \theta) /(d \alpha / d \theta)_{\alpha=0.5}$ and $(d \alpha / d t) /(d \alpha / d t)_{\alpha=0.5}$ are equivalent and $\mathrm{Eq}(16)$ becomes:

$$
\frac{(d \alpha / d t)}{(d \alpha / d t)_{0.5}}=\frac{x(1-x)^{L-1}}{x_{0.5}\left(1-x_{0.5}\right)^{L-1}}
$$

The generalized master plots for random scission mechanisms can now be constructed numerically by giving values to $\mathrm{x}$ and plotting Eq (17) against $\alpha$. The resulting curves are plotted in Fig 3 for different values of $\mathrm{L}$ and compared with the master plots corresponding to the rest of the kinetic models in Table 1. As it can be clearly noticed, random scission master plots could be distinguished easily due to the maximum they show at $\alpha$ values of around 0.275 . Diffusion and "n-order" master plots present no maximum while the master plots corresponding to nucleation and growth laws have it at $\alpha=0.4$ or higher.

\section{Experimental}

Commercial Polybutyleneterephtalate (Aldrich, product number 435147), polytetrafluoroethylene (Aldrich, product number 182478) and polyethylene (Aldrich, product number 332119, medium density $\mathrm{d}=0.940$ ) were used in this work. 
Thermogravimetry measurements were carried out with a homemade TGA instrument that uses a CI Electronics Ltd electrobalance connected to a gas flow system to work in inert atmosphere $\left(70 \mathrm{cc} \mathrm{min}^{-1} \mathrm{~N}_{2}\right)$. Small samples $(9 \mathrm{mg})$ were used in order to minimize heat and mass transfer phenomena. They were placed on a $1 \mathrm{~cm}$ diameter platinum pan inside a low thermal inertia homemade furnace. The instrument allows working either under conventional linear heating conditions or under constant rate conditions (CRTA). A description of the experimental set-up can be found in references. ${ }^{50-52}$

\section{Results and discussion}

\subsection{Evaluation of the model by simulated curves.}

As it has been stated before, the generalized master plots are valid whatever the experimental conditions used for recording the data. Hence, they will be tested by its application to curves simulated assuming both linear heating and controlled rate conditions. Fig $4 \mathrm{a}$ shows a set of $\alpha$-T curves simulated according to the following kinetic parameters: random scission $\mathrm{L}=2, \mathrm{E}=150 \mathrm{~kJ} \mathrm{~mol}^{-1}$ and $\mathrm{A}=10^{11} \mathrm{~s}^{-1}$. Curves were constructed assuming linear heating programs of 1,2 and $5 \mathrm{~K} \mathrm{~min}^{-1}$. Fig $4 \mathrm{~b}$ includes a curve simulated assuming the same kinetic parameters and a constant reaction rate of $0.06 \mathrm{~min}^{-1}$.

The activation energy was calculated by means of the Friedman isoconversional method, a model-free method used for estimating the activation energy as a function of the reacted fraction. ${ }^{5}$ Eq. (1) is a general equation that makes no assumption regarding the temperature profile under which the experimental data is recorded. Therefore, Friedman method can be applied simultaneously to kinetic data obtained under any 
heating profile. ${ }^{47,53}$ It should be noted that no previous assumption on the kinetic model fitted by the reaction is required. Eq. (1) can be written in logarithmic form:

$$
\ln \left(\frac{d \alpha}{d t}\right)=\ln (A f(\alpha))-\frac{E}{R T}
$$

The activation energy can be determined from the slope of the plot of the left hand side of Eq. (18) against the inverse of the temperature, at constant values of $\alpha$. As expected, a value for $\mathrm{E}$ of $150 \mathrm{~kJ} \mathrm{~mol}^{-1}$ and a linear correlation coefficient of 1 is obtained from Friedman analysis. Fig 5 contains the theoretical generalized master plots corresponding to some of the kinetic models included in Table 1 besides the random scission models here proposed. As random scission master plots are very similar only two of them have been included in the graph. Theoretical master plots were drawn by means of the fraction $f(\alpha) / f(0.5)$. The generalized master plot corresponding to the simulated curves, calculated according to Eq. (14) using the $150 \mathrm{~kJ} \mathrm{~mol}^{-1}$ activation energy obtained from Friedman method, are also included for comparison. Fig 5 illustrates clearly that the generalized master plots corresponding to the simulated curves match perfectly the one constructed according to L2 random scission models.

\subsection{Evaluation of the model by analyzing experimental data.}

In order to confirm the validity of the proposed equations, the same kinetic analysis by Friedman model-free and generalized master plots methods has been applied to the study of the thermal degradation of three commercial polymers: polybutylenterephtalate (PBT), polyethylene (PE) and polytetrafluoroethylene (PTFE). Experiments were performed in every case under both conventional linear heating and controlled rate conditions. The activation energy obtained in each case from the Friedman method has 
been used for the construction of the generalized master plots for obtaining the kinetic model followed by each decomposition process. Friedman method was selected for performing the kinetic analysis due to its capacity to yield accurate values for the activation energy even if it were a function of the reacted fraction. ${ }^{13}$

Fig 6 a includes a set of 3 experimental decomposition curves corresponding to the decomposition of PTFE that were recorded under linear heating conditions at 1,2 and 5 $\mathrm{K} \min ^{-1}$. Fig $6 \mathrm{~b}$ shows the decomposition curve obtained under a constant rate of $510^{-4}$ $\min ^{-1}$. All curves from Fig 6 were analyzed simultaneously by means of Friedman method using Eq. (18). In Table 2 the evolution of the activation energy with the degree of conversion is shown. The activation energy is approximately constant during the entire process and the correlation factors resulting from the analysis are 0.998 or higher. In order to determine the kinetic model the reaction follows, the generalized master plots for every experimental curve in Fig 6 are constructed according to Eq. (14), using the activation energy $\left(285 \mathrm{~kJ} \mathrm{~mol}^{-1}\right)$ obtained from the isoconversional analysis. The results are illustrated in Fig 7, where the experimental master plots are compared with those calculated assuming several ideal models, including the newly proposed random scission ones. It is clear from Fig 7 that experimental master plots appear to follow first order kinetics. A slight deviation is observed at low values of $\alpha$, which is due to the expected separation of the real process from the ideal model. It is noteworthy to point out that kinetic models listed in table 1 were proposed assuming certain ideal physical and geometrical conditions that are difficult to fulfill in real systems. This result is coincident with that obtained for this very same system in a previous work by means of a different kinetic analysis method. ${ }^{38}$

Fig 8 shows the experimental decomposition curves corresponding to the thermal degradation of polyethylene, recorded under both linear heating conditions at 1,2 and 
$10 \mathrm{~K} \mathrm{~min}^{-1}$ (Fig 8a); and a constant rate of $1.610^{-4} \mathrm{~min}^{-1}$ (Fig 8b). In Table 2 the activation energy as a function of $\alpha$ obtained from Friedman isoconversional method is shown. Again, correlation factors obtained from Friedman plots are over 0.996 and activation energy values that lie within a short range are obtained. Fig 9 shows the comparison between the generalized master plots, constructed from ideal kinetic models from table 1, and those constructed for each experimental curve in Fig 8 according to Eq. (14), using a value for the activation energy of $255 \mathrm{~kJ} \mathrm{~mol}^{-1}$, as obtained from the isoconversional analysis. The master plots obtained for experimental curves present a consistent shape that approximate a process driven by a diffusion mechanism, which corresponds nicely with the result obtained for this process in a previous paper by means of a combined kinetic analysis method. ${ }^{38}$

Lastly, Fig 10a includes a set of 3 experimental decomposition curves corresponding to the decomposition of PBT recorded under linear heating conditions at 1, 2 and $5 \mathrm{~K} \mathrm{~min}^{-}$ ${ }^{1}$ while Fig 10b shows the decomposition curve obtained under a constant rate of $1.410^{-}$ ${ }^{5} \min ^{-1}$. The activation energy calculated by means of Friedman method as a function of the degree of conversion is included in Table 2. Correlation factors are over 0.998 and the activation energy keeps a fairly constant value during the whole reaction, which indicates it is a one-step process. Generalized master plots are constructed using the value of the activation energy obtained from the isoconversional analysis $\left(182 \mathrm{~kJ} \mathrm{~mol}^{-1}\right)$, and plotted together with the master plots corresponding to the ideal kinetic models in Figure 11. This figure clearly illustrates that the shape of the generalized master plot curve corresponding to the thermal degradation of PBT has a very close resemblance to a random scission model, albeit somewhat displaced. This deviation can be attributed to the separation of real process from the ideal conditions the models assume. 


\section{Conclusions}

In this work, generalized master plots for reactions driven by random scission have been proposed for the first time. For that, Simha-Wall equations for the description of random scission mechanisms had to be reformulated in order to develop the $f(\alpha)$ conversion functions that are needed for the construction of the ideal random scission master plots. These new equations have been validated by its application to both simulated and experimental curves. Experimental data was obtained from the thermal degradation of three commercial polymers that decompose through three different mechanisms: polytetrafluoroethylene, polyethylene and poly(1,4-butylene)terephtalate. Experimental curves obtained under linear heating and sample controlled conditions have been analyzed simultaneously by Friedman model-free method, obtaining the activation energy characteristic for the process. On the other hand, the comparison between the master plots constructed from the experimental data and the plots constructed from the most usual kinetic models in literature has allowed for the deduction of the kinetic model that drives each thermal decomposition reaction. Therefore, first order, diffusion and random scission has been deduced as the mechanisms that govern the thermal degradation of polytetrafluoroethylene, polyethylene and poly(1,4-butylene)terephtalate, respectively. Additionally, it has been demonstrated that since random scission conversion functions are completely different from first order or "n-order" ones, random scission driven reactions could never be correctly described by means of "n-order" empirical models, as it is done frequently in the literature. 


\section{ACKNOWLEDGEMENT}

Financial support from projects TEP-03002 from Junta de Andalucía and MAT 2008-

06619/MAT from the Spanish Ministerio de Ciencia e Innovación is acknowledged.

\section{Bibliography}

(1) Khawam, A.; Flanagan, D. R. Solid-state kinetic models: Basics and mathematical fundamentals. Journal of Physical Chemistry B 2006, 110, 17315.

(2) Koga, N.; Tanaka, H. A physico-geometric approach to the kinetics of solidstate reactions as exemplified by the thermal dehydration and decomposition of inorganic solids. Thermochimica Acta 2002, 388, 41.

(3) Freeman, E. S.; Carroll, B. The application of termoanalytical techniques to reaction kinetics. Th thermogravimetric evaluation of the kinetics of the decomposition of calcium oxalate monohydrate. Journal of Physical Chemistry 1958, 62, 394.

(4) Maccallum.Jr; Tanner, J.; Freeman, E. S.; Carroll, B. Interpretation of kinetics of thermogravimetric analysis. Journal of Physical Chemistry 1969, 73, 751.

(5) Friedman, H. L. Kinetics of Thermal Degradation of Char-Forming Plastics from Thermogravimetry. Application to Phenolic Plastic Journal of Polymer Science Part C-Polymer Symposium 1964, 183.

(6) Perez-Maqueda, L. A.; Sanchez-Jimenez, P. E.; Criado, J. M. Kinetic analysis of solid-state reactions: Precision of the activation energy calculated by integral methods. International Journal of Chemical Kinetics 2005, 37, 658.

(7) Perez-Maqueda, L. A.; Sanchez-Jimenez, P. E.; Criado, J. M. Evaluation of the integral methods for the kinetic study of thermally stimulated processes in polymer science. Polymer 2005, 46, 2950.

(8) Sanchez-Jimenez, P. E.; Criado, J. M.; Perez-Maqueda, L. A. Kissinger kinetic analysis of data obtained under different heating schedules. Journal of Thermal Analysis and Calorimetry 2008, 94, 427.

(9) Kissinger, H. E. Variation of peak temperature with heating rate in differential thermal analysis. Journal of Research of the National Bureau of Standards 1956, 57, 217.

(10) Vyazovkin, S. A unified approach to kinetic processing of nonisothermal data. International Journal of Chemical Kinetics 1996, $28,95$.

(11) Vyazovkin, S. Kinetic concepts of thermally stimulated reactions in solids: a view from a historical perspective. International Reviews in Physical Chemistry 2000, 19, 45.

(12) Vyazovkin, S.; Wight, C. A. Model-free and model-fitting approaches to kinetic analysis of isothermal and nonisothermal data. Thermochimica Acta 1999, 340/341, 53.

(13) Criado, J. M.; Sanchez-Jimenez, P. E.; Perez-Maqueda, L. A. Critical study of the isoconversional methods of kinetic analysis. Journal of Thermal Analysis and Calorimetry 2008, $92,199$.

(14) Vyazovkin, S. Model-free kinetics - Staying free of multiplying entities without necessity. Journal of Thermal Analysis and Calorimetry 2006, 83, 45.

(15) Khawam, A.; Flanagan, D. R. Role of isoconversional methods in varying activation energies of solid-state kinetics - II. Nonisothermal kinetic studies. Thermochimica Acta 2005, 436, 101. 
(16) Mamleev, V.; Bourbigot, S.; Le Bras, M.; Lefebvre, J. Three model-free methods for calculation of activation energy in TG. Journal of Thermal Analysis and Calorimetry 2004, $78,1009$.

(17) Opfermann, J. R.; Kaisersberger, E.; Flammersheim, H. J. Model-free analysis of thermoanalytical data-advantages and limitations. Thermochimica Acta 2002, 391, 119.

(18) Vyazovkin, S. Modification of the integral isoconversional method to account for variation in the activation energy. Journal of Computational Chemistry 2001, 22, 178.

(19) Vyazovkin, S.; Sbirrazzuoli, N. Isoconversional kinetic analysis of thermally stimulated processes in polymers. Macromolecular Rapid Communications 2006, 27, 1515.

(20) Criado, J. M.; Malek, J.; Ortega, A. Applicability of the master plots in the kinetic analysis of non-isothermal data. Thermochimica Acta 1989, 147, 377.

(21) Criado, J. M.; Perez-Maqueda, L. A.; Gotor, F. J.; Malek, J.; Koga, N. A unified theory for the kinetic analysis of solid state reactions under any thermal pathway. Journal of Thermal Analysis and Calorimetry 2003, 72, 901.

(22) PerezMaqueda, L. A.; Ortega, A.; Criado, J. M. The use of master plots for discriminating the kinetic model of solid state reactions from a single constant-rate thermal analysis (CRTA) experiment. Thermochimica Acta 1996, 277, 165.

(23) Gotor, F. J.; Criado, J. M.; Malek, J.; Koga, N. Kinetic analysis of solid-state reactions: The universality of master plots for analyzing isothermal and nonisothermal experiments. Journal of Physical Chemistry A 2000, 104, 10777.

(24) Pielichowski, J.; Njuguna, J. Thermal Degradation of Polimeric Materials: Rapra Technology Ltd: Shawbury, 2005.

(25) Habibi, A.; De Wilde, J. Kinetic modeling of the thermal degradation of methacrylate copolymers by thermogravimetric methods. International Journal of Chemical Reactor Engineering 2007, 5, 18.

(26) Mamleev, V.; Bourbigot, S.; Le Bras, M.; Yvon, J.; Lefebvre, J. Model-free method for evaluation of activation energies in modulated thermogravimetry and analysis of cellulose decomposition. Chemical Engineering Science 2006, 61, 1276.

(27) Vyazovkin, S.; Sbirrazzuoli, N. Isoconversional analysis of calorimetric data on nonisothermal crystallization of a polymer melt. Journal of Physical Chemistry B 2003, 107, 882.

(28) Vyazovkin, S.; Dranca, I.; Fan, X. W.; Advincula, R. Degradation and relaxation kinetics of polystyrene - Clay nanocomposite prepared by surface initiated polymerization. Journal of Physical Chemistry B 2004, 108, 11672.

(29) Gao, Z. M.; Kaneko, T.; Hou, D. Y.; Nakada, M. Kinetics of thermal degradation of poly(methyl methacrylate) studied with the assistance of the fractional conversion at the maximum reaction rate. Polymer Degradation and Stability 2004, 84, 399.

(30) Paik, P.; Kar, K. K. Thermal degradation kinetics and estimation of lifetime of polyethylene particles: Effects of particle size. Materials Chemistry and Physics 2009, 113, 953.

(31) Ceamanos, J.; Mastral, J. F.; Millera, A.; Aldea, M. E. Kinetics of pyrolysis of high density polyethylene. Comparison of isothermal and dynamic experiments. Journal of Analytical and Applied Pyrolysis 2002, 65, 93.

(32) Inoue, E.; Tsuchiya, M.; Ishimaru, K.; Kojima, T. Thermogravimetric studies on poly(methyl methacrylate), poly(tetrahydrofuran) and their blends. Journal of Thermal Analysis and Calorimetry 2002, 70, 747.

(33) Conesa, J. A.; Font, R. Polytetrafluoroethylene decomposition in air and nitrogen. Polymer Engineering and Science 2001, 41, 2137.

(34) Liu, N.; Chen, H.; Shu, L.; Statheropoulos, M. Error evaluation of integral methods by consideration on the approximation of temperature integral. Journal of Thermal Analysis and Calorimetry 2005, 81, 99.

(35) Gao, Z. M.; Amasaki, I.; Nakada, M. A thermogravimetric study on thermal degradation of polyethylene. Journal of Analytical and Applied Pyrolysis 2003, 67, 1. 
(36) Lu, L.; Yu, H. Y.; Wang, S. F.; Zhang, Y. Thermal Degradation Behavior of Styrene-Butadiene-Styrene Tri-Block Copolymer/Multiwalled Carbon Nanotubes Composites. Journal of Applied Polymer Science 2009, 112, 524.

(37) Garcia, N.; Hoyos, M.; Guzman, J.; Tiemblo, P. Comparing the effect of nanofillers as thermal stabilizers in low density polyethylene. Polymer Degradation and Stability 2009, 94, 39.

(38) Sanchez-Jimenez, P. E.; Perez-Maqueda, L. A.; Perejon, A.; Criado, J. M. Combined kinetic analysis of thermal degradation of polymeric materials under any thermal pathway. Polymer Degradation and Stability 2009, 94, 2079.

(39) Choukourov, A.; Grinevich, A.; Polonskyi, O.; Hanus, J.; Kousal, J.; Slavinska, D.; Biederman, H. Vacuum Thermal Degradation of Poly(ethylene oxide). Journal of Physical Chemistry B 2009, 113, 2984.

(40) Caceres, C. A.; Canevarolo, S. V. Chain Scission in the Thermo Mechanical Degradation of Polystyrene under Multiple Extrusions. Polimeros-Ciencia E Tecnologia 2008, 18,348 .

(41) Zhou, X. M. Thermal Behavior of PES/PEES Copolymers with Different Sequence Distribution: Comparative Study of the Kinetics of Degradation. Journal of Applied Polymer Science 2009, 111, 833.

(42) Sanchez-Jimenez, P. E.; Perez-Maqueda, L. A.; Perejon, A.; Criado, J. M. A new model for the kinetic analysis of thermal degradation of polymers driven by random scission. Polymer Degradation and Stability 2010, 95, 733.

(43) Daraboina, N.; Madras, G. Thermal and photocatalytic degradation of poly(methyl methacrylate), poly(butyl methacrylate), and their copolymers. Industrial \& Engineering Chemistry Research 2008, 47, 6828.

(44) Liu, Y.; Wei, R. Q.; Wei, J.; Liu, X. N. Thermal Degradation of Poly(L-Lactide) with High Molecular Weight into L-Lactide. Progress in Chemistry 2008, 20, 1588.

(45) Wallis, M. D.; Bhatia, S. K. Thermal degradation of high density polyethylene in a reactive extruder. Polymer Degradation and Stability 2007, 92, 1721.

(46) Simha, R.; Wall, L. A. Kinetics of chain depolymerization Journal of Physical Chemistry 1952, 56, 707.

(47) Perez-Maqueda, L. A.; Criado, J. M.; Sanchez-Jimenez, P. E. Combined kinetic analysis of solid-state reactions: A powerful tool for the simultaneous determination of kinetic parameters and the kinetic model without previous assumptions on the reaction mechanism. Journal of Physical Chemistry A 2006, 110, 12456.

(48) Ozawa, T. A new method for analyzing thermogravimetric data Bulletin of the Chemical Society of Japan 1965, 38, 1881.

(49) Ozawa, T. Nonisothermal kinetics and the generalized time Thermochimica Acta 1986, 100, 109.

(50) Criado, J. M.; Perez-Maqueda, L. A.; Dianez, M. J.; Sanchez-Jimenez, P. E. Development of a universal constant rate thermal analysis system for being used with any thermoanalytical instrument. Journal of Thermal Analysis and Calorimetry 2007, 87, 297.

(51) Alcala, M. D.; Criado, J. M.; Gotor, F. J.; Ortega, A.; Perez Maqueda, L. A.; Real, C. Development of a new thermogravimetric system for performing constant rate thermal analysis (CRTA) under controlled atmosphere at pressures ranging from vacuum to 1 bar. Thermochim. Acta 1994, 240, 167.

(52) Dianez, M. J.; Perez-Maqueda, L. A.; Criado, J. M. Direct use of the mass output of a thermobalance for controlling the reaction rate of solid-state reactions. Review of Scientific Instruments 2004, 75, 2620.

(53) Perez-Maqueda, L. A.; Criado, J. M.; Gotor, F. J.; Malek, J. Advantages of combined kinetic analysis of experimental data obtained under any heating profile. Journal of Physical Chemistry A 2002, 106, 2862. 

proposed random scission model.

\begin{tabular}{ccc}
\hline Mechanism & Symbol & $\mathbf{f}(\alpha)$ \\
\hline $\begin{array}{c}\text { Phase boundary controlled reaction } \\
\text { (contracting area) }\end{array}$ & $\mathrm{R} 2$ & $(1-\alpha)^{1 / 2}$ \\
$\begin{array}{c}\text { Phase boundary controlled reaction } \\
\text { (contracting volume) }\end{array}$ & $\mathrm{R} 3$ & $(1-\alpha)^{2 / 3}$ \\
Random nucleation followed by an \\
instantaneous growth of nuclei. \\
$\quad$ (Avrami-Erofeev eqn. $n=1)$
\end{tabular}

Random nucleation and growth of nuclei through different nucleation and nucleus An $\quad n(1-\alpha)[-\ln (1-\alpha)]^{1-1 / n}$ growth models. (Avrami-Erofeev eqn $\neq 1$.)

\begin{tabular}{ccc} 
Two-dimensional diffusion & D2 & $1 /[-\ln (1-\alpha)]$ \\
$\begin{array}{c}\text { Three-dimensional diffusion } \\
\text { (Jander equation) }\end{array}$ & D3 & $2\left[1-(1-\alpha)^{1 / 3}\right]$ \\
$\begin{array}{c}\text { Three-dimensional diffusion } \\
\text { (Ginstling-Brounshtein equation) }\end{array}$ & D4 & $2\left[(1-\alpha)^{-1 / 3}-1\right]$ \\
Random Scission L=2 & L2 & $2\left(\alpha^{1 / 2}-\alpha\right)$ \\
Random Scission L $>2$ & Ln & No symbolic solution \\
\hline
\end{tabular}


TABLE 2. Activation energy values at different values of conversion and their correlation coefficients, obtained by the Friedman isoconversional analysis of the thermal decomposition of polytetrafluoroethylene (PTFE), polyethylene (PE) and poly(1,4-butylen) terephtalate (PBT).

\begin{tabular}{ccc|ccc|ccc}
\hline \multicolumn{3}{c}{ PFTE } & \multicolumn{3}{c}{ PE } & \multicolumn{3}{c}{ PBT } \\
\hline $\boldsymbol{\alpha}$ & $\mathbf{R}$ & $\begin{array}{c}\text { Ea } \\
\left(\mathbf{k J m o l}^{-1}\right)\end{array}$ & $\boldsymbol{\alpha}$ & $\mathbf{R}$ & $\begin{array}{c}\text { Ea } \\
\left(\mathrm{kJmol}^{-1}\right)\end{array}$ & $\boldsymbol{\alpha}$ & $\mathbf{R}$ & $\begin{array}{c}\text { Ea } \\
\left(\mathbf{k J m o l}^{-1}\right)\end{array}$ \\
\hline 0.1 & 0.998 & $299 \pm 6$ & 0.1 & 0.997 & $246 \pm 8$ & 0.1 & 0.999 & $182 \pm 4$ \\
0.2 & 1.000 & $286 \pm 3$ & 0.2 & 0.996 & $246 \pm 16$ & 0.2 & 1.000 & $182 \pm 4$ \\
0.3 & 1.000 & $282 \pm 4$ & 0.3 & 0.999 & $259 \pm 10$ & 0.3 & 1.000 & $180 \pm 4$ \\
0.4 & 0.999 & $286 \pm 6$ & 0.4 & 0.998 & $256 \pm 13$ & 0.4 & 1.000 & $180 \pm 4$ \\
0.5 & 0.999 & $285 \pm 5$ & 0.5 & 0.998 & $255 \pm 13$ & 0.5 & 1.000 & $181 \pm 3$ \\
0.6 & 1.000 & $282 \pm 4$ & 0.6 & 0.999 & $259 \pm 9$ & 0.6 & 1.000 & $182 \pm 3$ \\
0.7 & 0.999 & $280 \pm 4$ & 0.7 & 0.998 & $254 \pm 11$ & 0.7 & 1.000 & $183 \pm 2$ \\
0.8 & 0.998 & $291 \pm 8$ & 0.8 & 0.998 & $255 \pm 10$ & 0.8 & 1.000 & $185 \pm 2$ \\
0.9 & 0.998 & $296 \pm 9$ & 0.9 & 0.997 & $260 \pm 11$ & 0.9 & 0.999 & $195 \pm 5$ \\
\hline
\end{tabular}




\section{Figure Captions}

Figure 1: Relationship between the actual fraction of bonds broken $(\mathrm{x})$ and the conversion, $\alpha$, for different random scission kinetic functions, according to Eq. (4). The rightmost curve was plotted assuming $\mathrm{L}=2$ while the leftmost for $\mathrm{L}=8$. Curves assuming $\mathrm{L}=3$ to $\mathrm{L}=7$ lie in-between them.

Figure 2: The $f(\alpha)$ conversion functions for: (a) the newly proposed random scission model, plus the different kinetic models most commonly used in literature, (b) diffusion controlled, (c) "n order" and (d) nucleation and growth kinetic models.

Figure 3: Generalized master plots corresponding to the different kinetic models in Table 1 as constructed from Eq. (13) and (17). (a) Random scission models; (b) diffusion controlled models; (c) "n order" models and (d) nucleation and growth models.

Figure 4. Curves simulated assuming a random scission L2 model, $\mathrm{E}=150 \mathrm{kJmol}^{-1}$, $\mathrm{A}=10^{11} \mathrm{~s}^{-1}$ and the following heating profiles: (a) linear heating rate of 1,2 and $5 \mathrm{~K} \mathrm{~min}^{-}$ ${ }^{1}$ and (b) controlled rate of $0.06 \mathrm{~min}^{-1}$.

Figure 5. Comparison between the generalized master plots constructed for the different simulated curves included in Figure 4 (symbols) and the master plots corresponding to some of the ideal kinetic models included in table 1 (solid lines).

Figure 6. Experimental curves obtained for the thermal decomposition of polytetrafluoroethylene under the following experimental conditions: (a) linear heating rate of 1,2 and $5 \mathrm{~K} \mathrm{~min}^{-1}$ and (b) sample controlled degradation rate of $510^{-4} \mathrm{~min}^{-1}$. 
Figure 7. Comparison between the generalized master plots corresponding to the experimental curves in Fig 6 with the theoretical master plots constructed from the ideal kinetic models in Table 1.

Figure 8. Experimental curves obtained for the thermal decomposition of polyethylene under the following experimental conditions: (a) linear heating rate of 1,2 and $10 \mathrm{~K}$ $\min ^{-1}$ and (b) sample controlled degradation rate of $1.610^{-4} \mathrm{~min}^{-1}$.

Figure 9. Comparison between the generalized master plots corresponding to the experimental curves in Fig 9 with the theoretical master plots constructed from the ideal kinetic models in Table 1.

Figure 10. Experimental curves obtained for the thermal decomposition of poly(1,4butylene)terephtalate under the following experimental conditions: (a) linear heating rate of 1,2 and $5 \mathrm{~K} \mathrm{~min}^{-1}$ and (b) sample controlled degradation rate of $1.410^{-5} \mathrm{~min}^{-1}$.

Figure 11. Comparison between the generalized master plots corresponding to the experimental curves in Fig 10 with the theoretical master plots constructed from the ideal kinetic models in Table 1. 


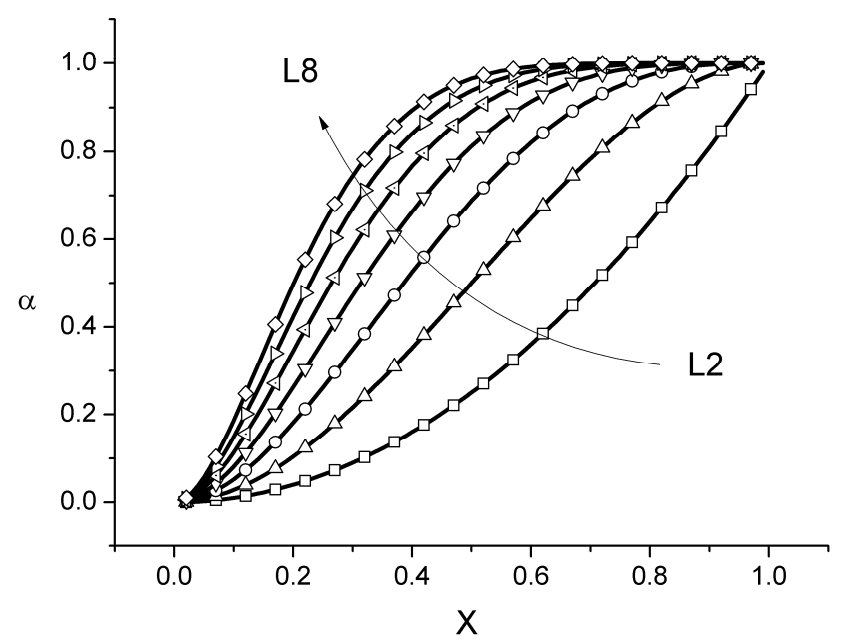

Figure 1: Relationship between the actual fraction of bonds broken (x) and the conversion, $\alpha$, for different random scission kinetic functions, according to Eq. (4). The rightmost curve was plotted assuming $\mathrm{L}=2$ while the leftmost for $\mathrm{L}=8$. Curves assuming $\mathrm{L}=3$ to $\mathrm{L}=7$ lie in-between them. 

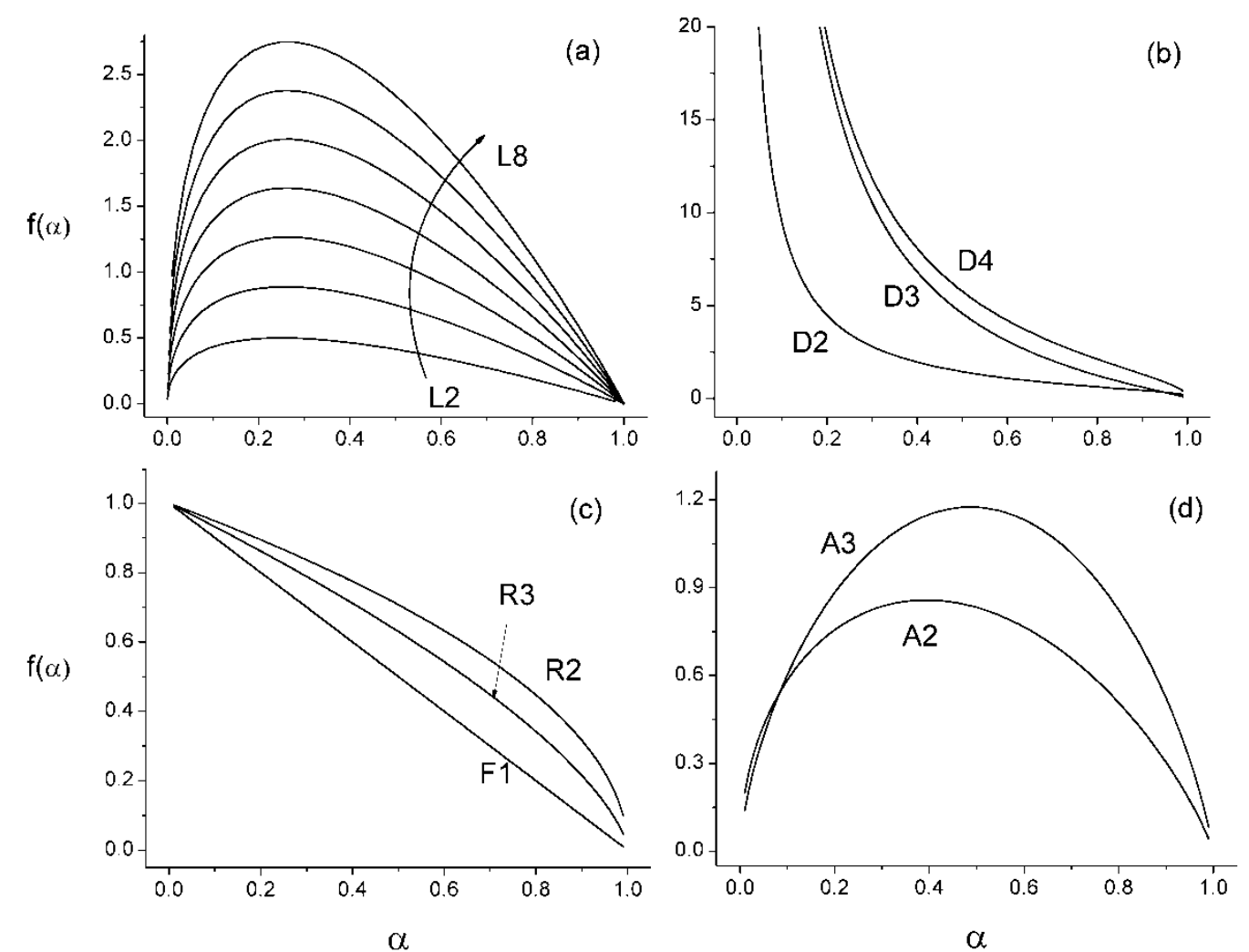

Figure 2: The $f(\alpha)$ conversion functions for: (a) the newly proposed random scission model, plus the different kinetic models most commonly used in literature, (b) diffusion controlled, (c) "n order" and (d) nucleation and growth kinetic models. 

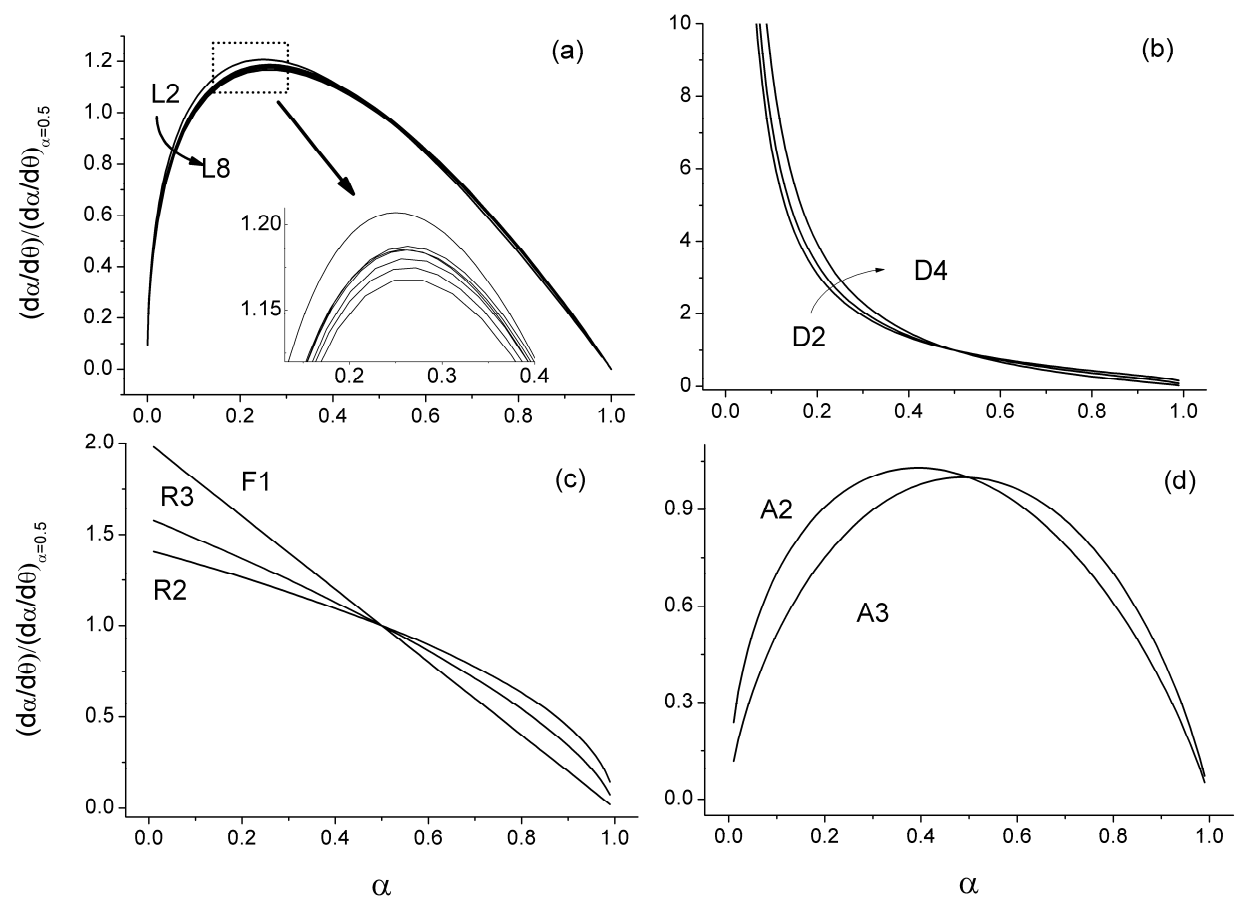

Figure 3: Generalized master plots corresponding to the different kinetic models in Table 1 as constructed from Eq. (13) and (17). (a) Random scission models; (b) diffusion controlled models; (c) "n order" models and (d) nucleation and growth models. 

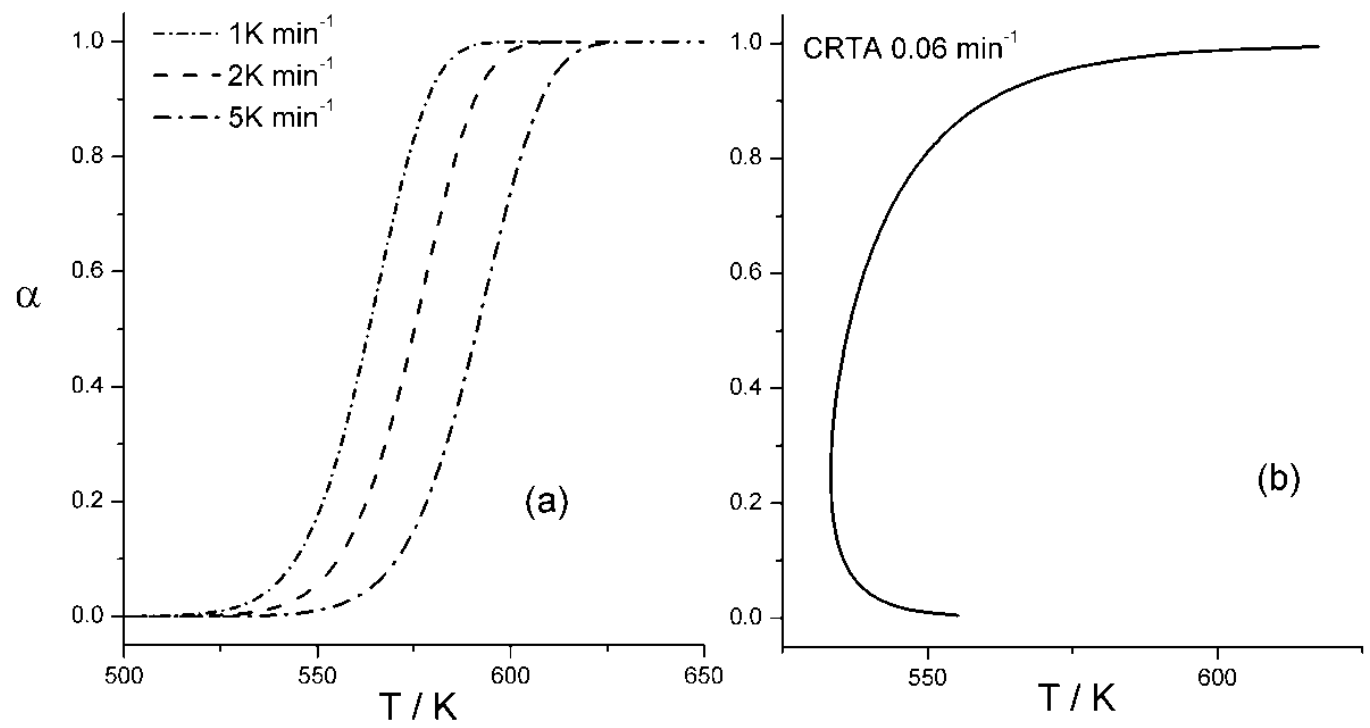

Figure 4. Curves simulated assuming a random scission L2 model, E = $150 \mathrm{kJmol}^{-1}, \mathrm{~A}=10^{11} \mathrm{~s}^{-1}$ and the following heating profiles: (a) linear heating rate of 1,2 and $5 \mathrm{~K} \mathrm{~min}^{-1}$ and (b) controlled rate of $0.06 \mathrm{~min}^{-1}$. 


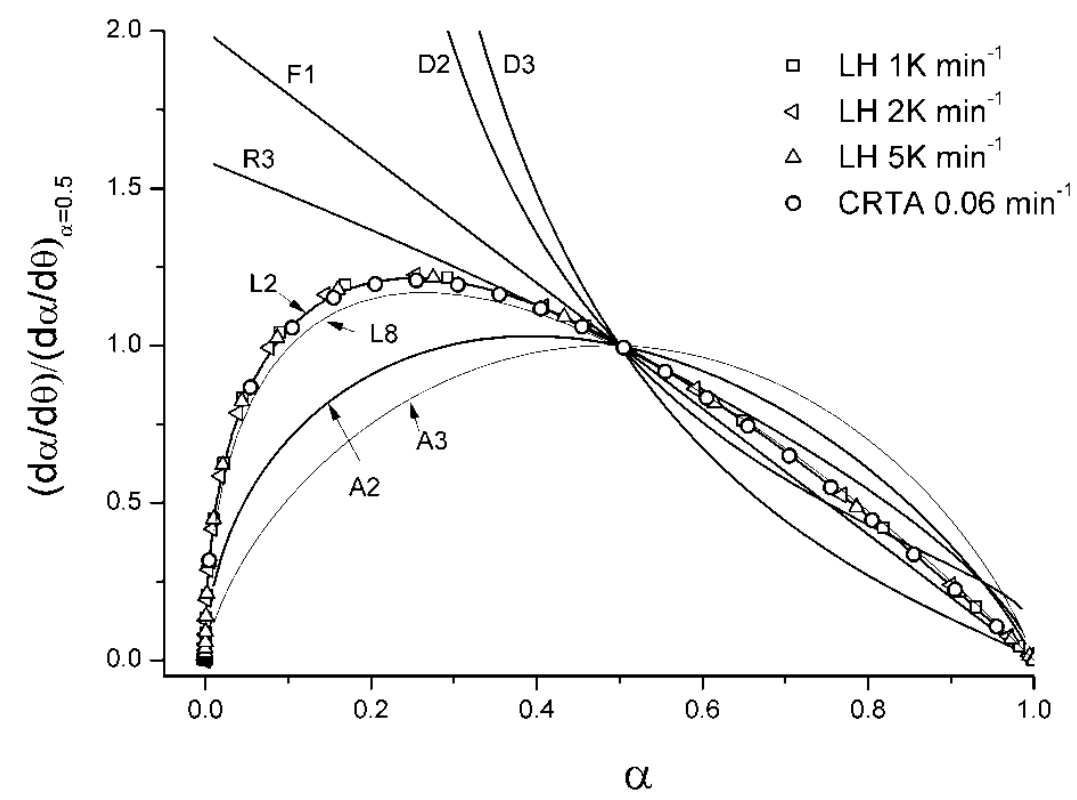

Figure 5. Comparison between the generalized master plots constructed for the different simulated curves included in Figure 4 (symbols) and the master plots corresponding to some of the ideal kinetic models included in table 1 (solid lines). 


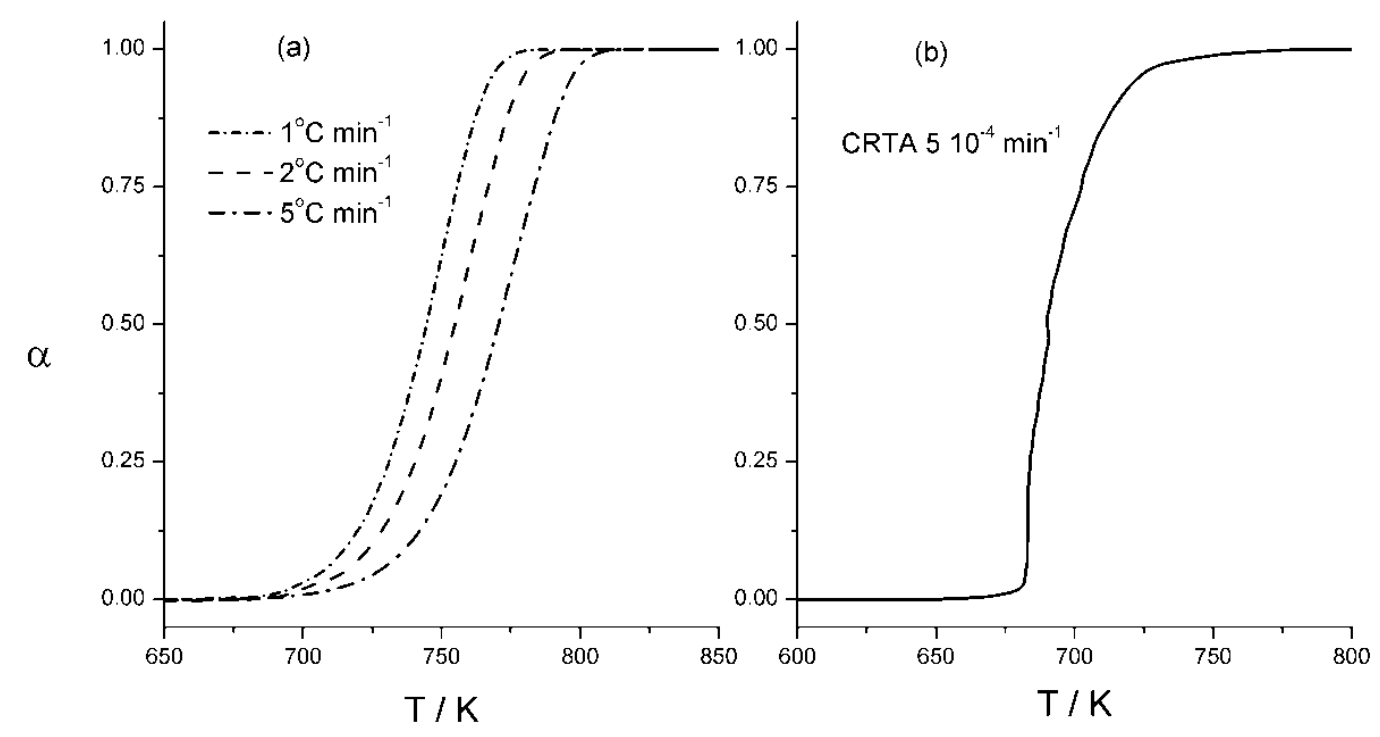

Figure 6. Experimental curves obtained for the thermal decomposition of polytetrafluoroethylene under the following experimental conditions: (a) linear heating rate of 1,2 and $5 \mathrm{~K} \mathrm{~min}^{-1}$ and (b) sample controlled degradation rate of $510^{-4} \mathrm{~min}^{-1}$. 


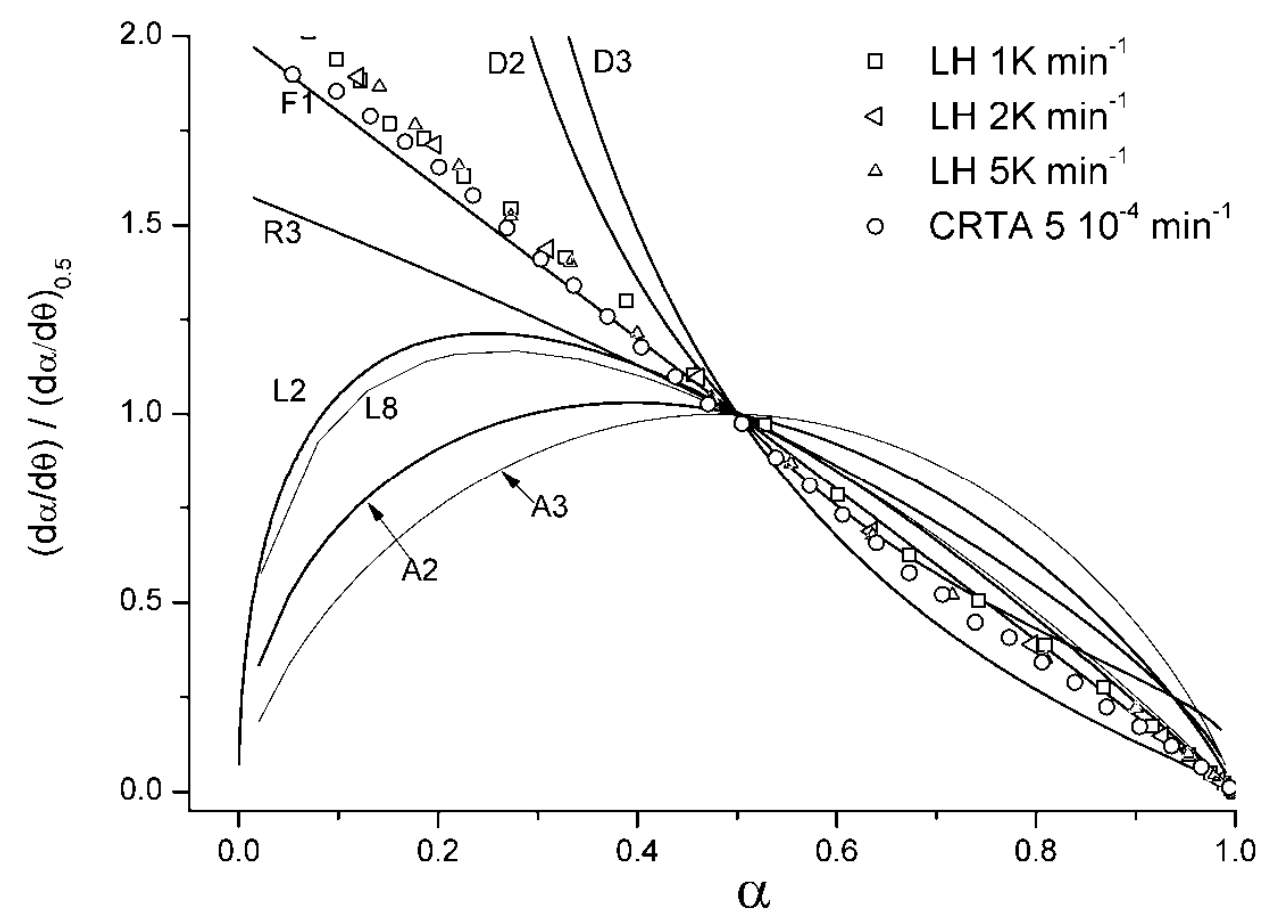

Figure 7. Comparison between the generalized master plots corresponding to the experimental curves in Fig 6 with the theoretical master plots constructed from the ideal kinetic models in Table 1. 


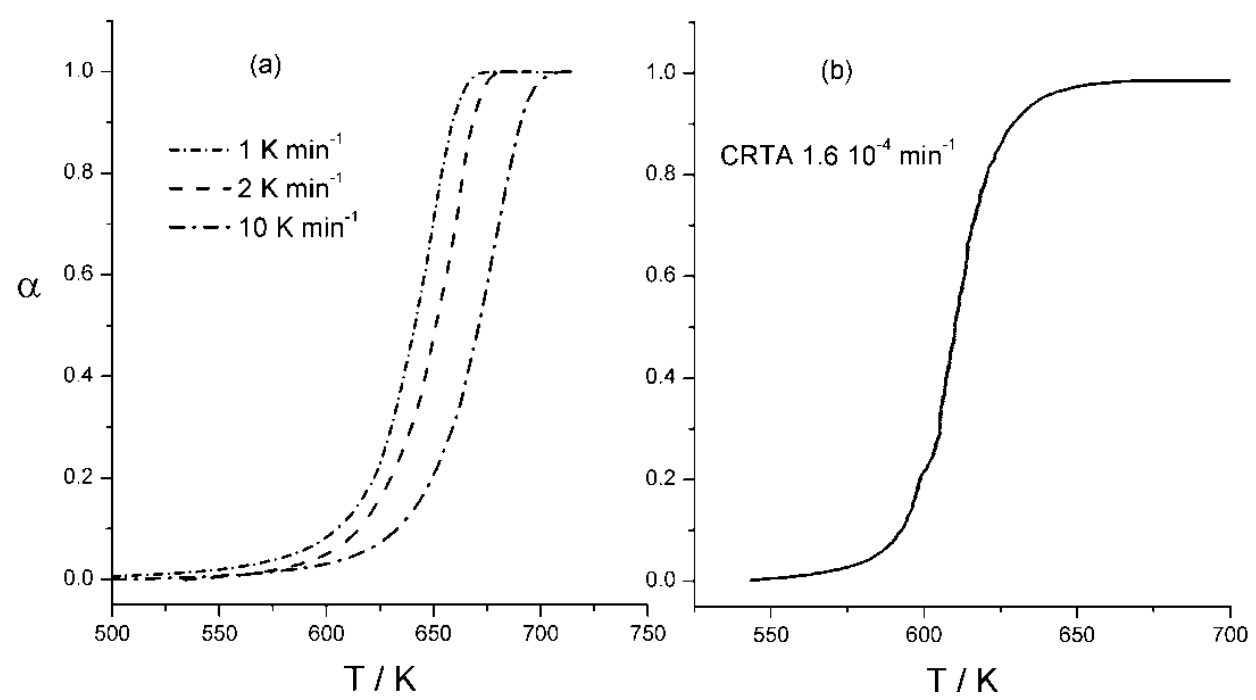

Figure 8. Experimental curves obtained for the thermal decomposition of polyethylene under the following experimental conditions: (a) linear heating rate of 1,2 and $10 \mathrm{~K} \mathrm{~min}^{-1}$ and (b) sample controlled degradation rate of $1.610^{-4} \mathrm{~min}^{-1}$. 


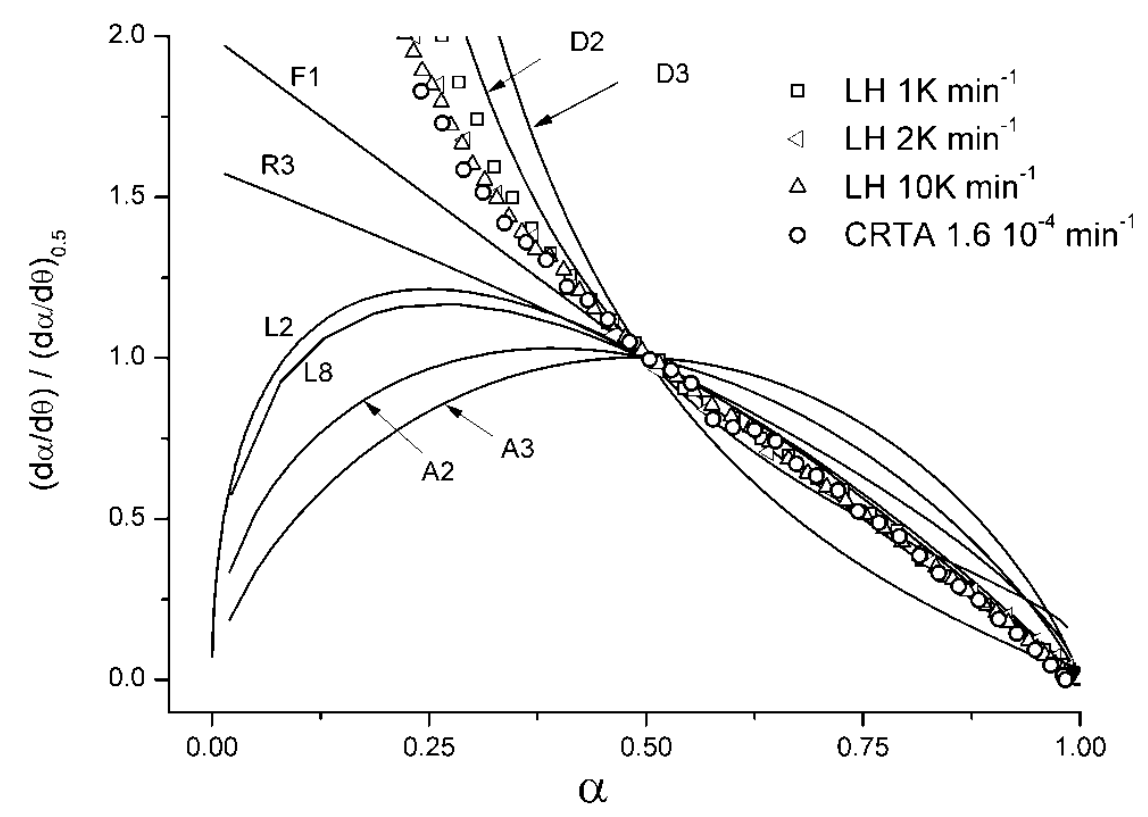

Figure 9. Comparison between the generalized master plots corresponding to the experimental curves in Fig 9 with the theoretical master plots constructed from the ideal kinetic models in Table 1. 

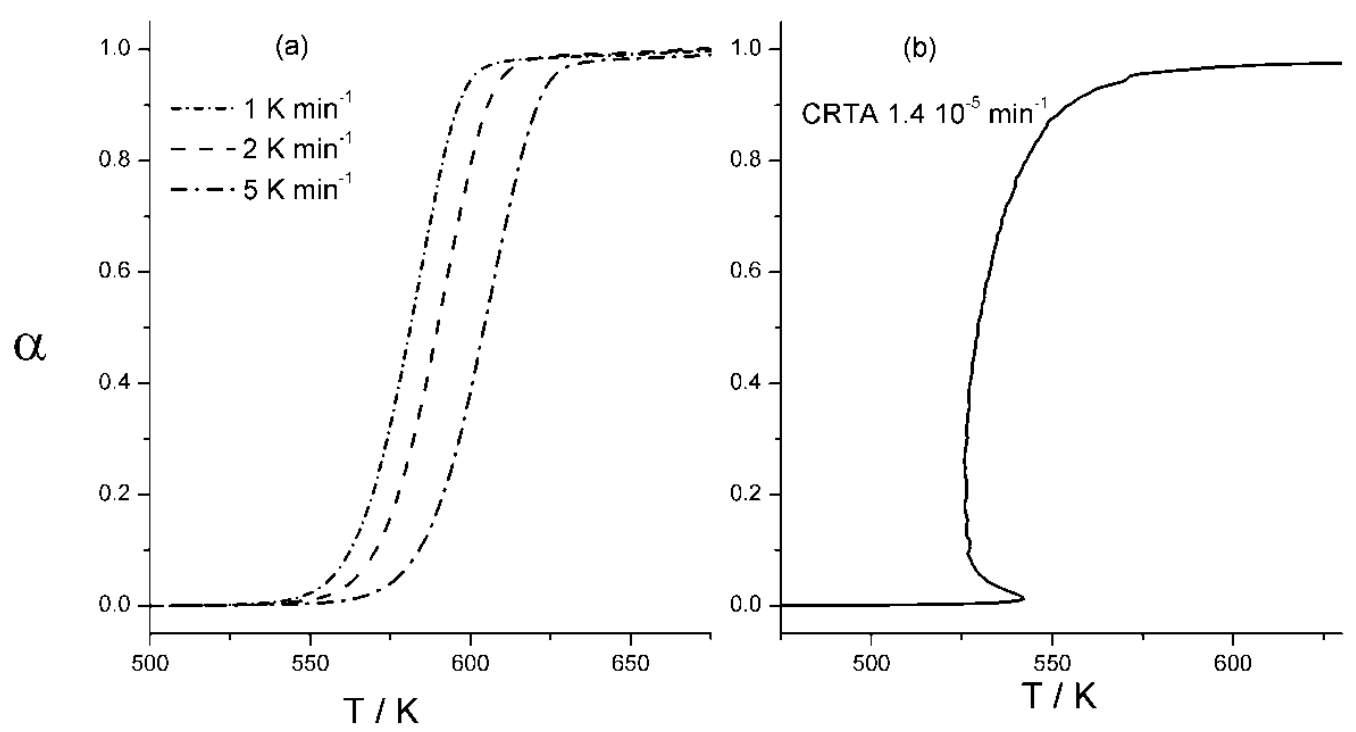

Figure 10. Experimental curves obtained for the thermal decomposition of poly(1,4-butylene)terephtalate under the following experimental conditions: (a) linear heating rate of 1, 2 and $5 \mathrm{~K} \mathrm{~min}^{-1}$ and (b) sample controlled degradation rate of $1.410^{-5} \mathrm{~min}^{-1}$. 


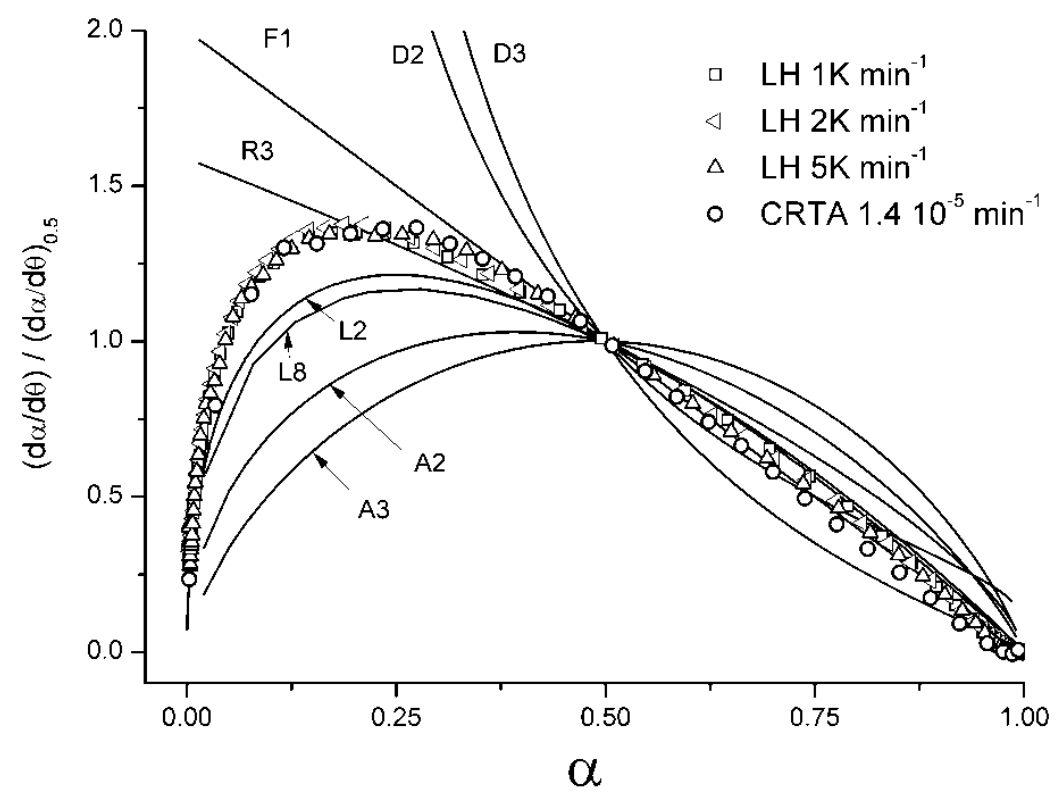

Figure 11. Comparison between the generalized master plots corresponding to the experimental curves in Fig 10 with the theoretical master plots constructed from the ideal kinetic models in Table 1. 
TABLE OF CONTENTS IMAGE

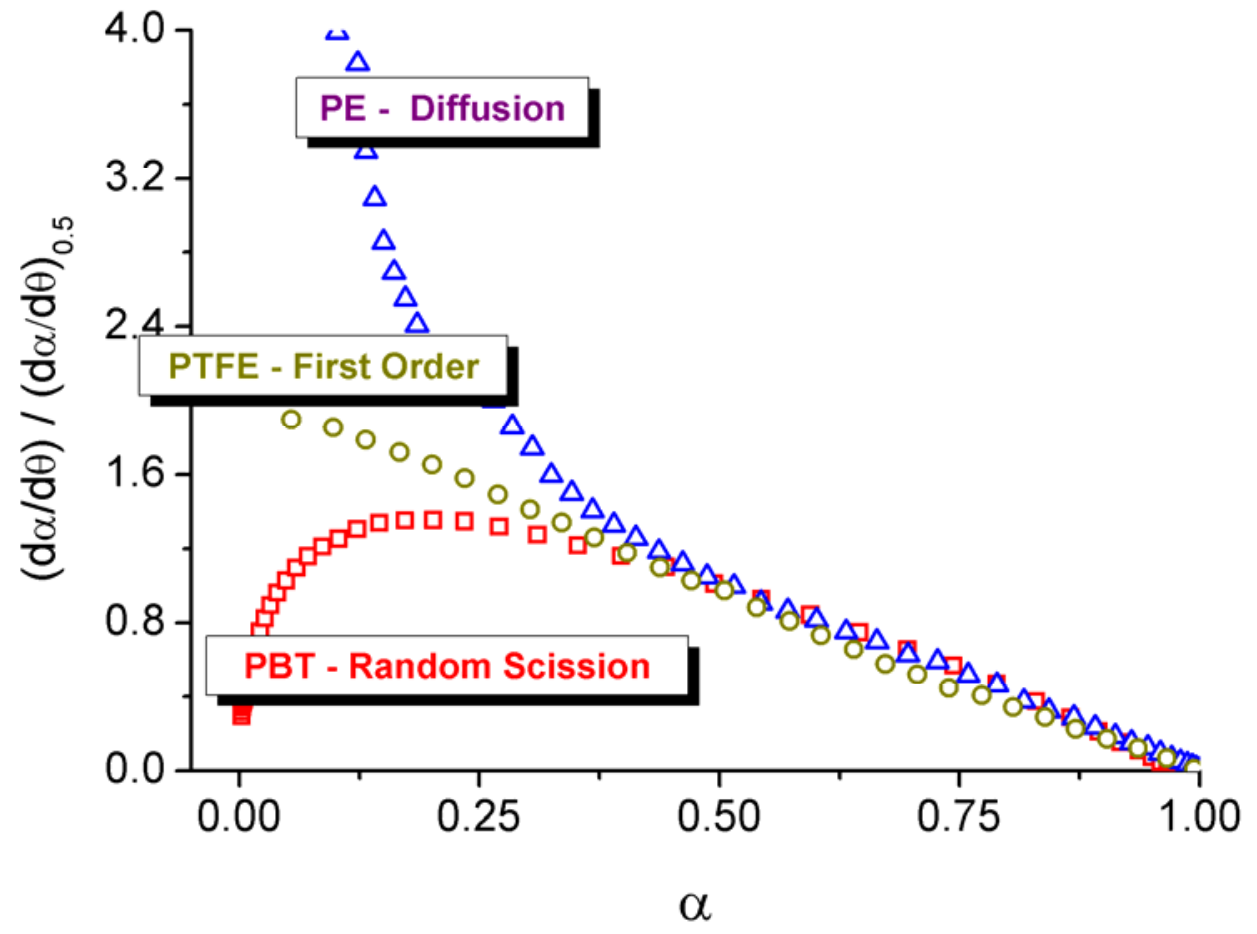

